\title{
The Utilization of Modified Zeolite for the Removal of Cs Ions in an Aqueous Solution: Adsorption Capacity, Isotherms, Kinetics and Microscopic Studies
}

\author{
Junfang Sun ${ }^{1}$, Ji Chen ${ }^{2}$, Xiang Peng ${ }^{1, *}$, Yu Zhang ${ }^{2}$, Jialin Mo ${ }^{2,3, *}$, Xin Liao ${ }^{4,5}$ and Qiang Tang ${ }^{2,6}$ \\ 1 Dongwu Business School, Soochow University, Suzhou 215021, China; jfsun@suda.edu.cn \\ 2 Graduate School of Global Environmental Studies, Kyoto University, Kyoto 606-8501, Japan; \\ chen.ji.68s@st.kyoto-u.ac.jp (J.C.); zhang.yu.54r@st.kyoto-u.ac.jp (Y.Z.); tangqiang@suda.edu.cn (Q.T.) \\ 3 National Institute for Environmental Studies, Fukushima Branch, Miharu 963-7700, Japan \\ 4 Faculty of Geosciences and Environmental Engineering, Southwest Jiaotong University, \\ Chengdu 611756, China; xinliao@swjtu.edu.cn \\ 5 MOE Key Laboratory of High-Speed Railway Engineering, Southwest Jiaotong University, \\ Chengdu 611756, China \\ 6 School of Rail Transportation, Soochow University, Suzhou 215131, China \\ * Correspondence: pengxiang@suda.edu.cn (X.P.); mo.jialin@nies.go.jp (J.M.)
}

\section{check for} updates

Citation: Sun, J.; Chen, J.; Peng, $X$.; Zhang, Y.; Mo, J.; Liao, X.; Tang, Q. The Utilization of Modified Zeolite for the Removal of Cs Ions in an Aqueous Solution: Adsorption Capacity, Isotherms, Kinetics and Microscopic Studies. Sustainability 2022, 14, 2615. https://doi.org/ $10.3390 /$ su14052615

Academic Editors: Rui Zhao,

Tianxue Yang and Sebastiano Patti

Received: 23 January 2022

Accepted: 22 February 2022

Published: 24 February 2022

Publisher's Note: MDPI stays neutral with regard to jurisdictional claims in published maps and institutional affiliations.

Copyright: (c) 2022 by the authors. Licensee MDPI, Basel, Switzerland. This article is an open access article distributed under the terms and conditions of the Creative Commons Attribution (CC BY) license (https:// creativecommons.org/licenses/by/ $4.0 /)$.

\begin{abstract}
Nuclear energy is a double-edged technology, which has a significant role in the chemical industry, but may bring about radioactivity and destruction. The 2011 Fukushima nuclear power plant accident caused by a tsunami, which flooded and led to tens of millions of disaster debris and tsunami deposits, severely disrupted the electricity supply in Japan and induced USD 211 billion worth of direct economic losses. $\mathrm{Cs}^{+}$was easily dissolved in this accident, had a high chemical activity, and thus required an appropriate adsorption method. Zeolite is an effective removal adsorbent, which is suitable to be investigated. The present study uses natural zeolite and three inorganic modified zeolites. Furthermore, the effects of various factors are investigated. Kinetic models and the isothermal adsorption mechanism are also conducted. For microscale studies for the adsorption mechanism, scanning electron microscope (SEM) and X-ray diffraction (XRD) were involved in the study. The results indicate that the optimal dosage is $1.1 \mathrm{~g}$ and the maximum adsorption rate is around $80 \%$. An alkaline environment is more conducive to the occurrence of adsorption. As for the isotherm and kinetic studies, the data fits better with the Redlich-Peterson isothermal model and intragranular diffusion model. In this small-scale experiment, the highest adsorption capacity was for Mg-zeolite at $6.53 \mathrm{mg} / \mathrm{g}$. Finally, Mg-Zeolite presents the best adsorption capacity.
\end{abstract}

Keywords: cesium; modified zeolite; adsorption; isotherms and kinetics; micro-scope characterization

\section{Introduction}

Nuclear energy represents an important component in the chemical industry and plays an important role in power transmission, medical devices and many other fields in our society. However, nuclear energy has become a double-edged technology because of its radioactivity and destructiveness [1]. The most typical case is the Fukushima nuclear power plant accident that occurred on 11 March 2011, caused by a tsunami. The tsunami was induced by the Tohoku Earthquake with a Richter magnitude scale of 9.0. Then, the $16 \mathrm{~m}$ high tsunami flooded an $80 \mathrm{~km}$ area, completely destroyed 129,391 houses, and damaged 1,008,394 [2], leaving almost $2.3 \times 10^{7}$ tons of disaster debris and more than 12 million $\mathrm{m}^{3}$ of tsunami deposits [3,4]. Following this event, many geo-environmental issues emerged, such as the disposal of the disaster debris and deposit, the treatment of soil and groundwater contamination, settlements being left in a severe state as a result of the nuclear accident, and other issues concerning the economy or human beings [5]. Among these, the biggest threat was the nuclear accident, which led to the release of many kinds of 
radionuclide over several days after the explosion. After the accident, Japan announced the SAMG (Severe Accident Management Guideline) for the management of the disaster, but it seems unable to stop the progression of the accident because of the continuous and sustainable release of radionuclides [6,7]. These radionuclides dissolved in seawater and may cause the migration of the groundwater in Japan, and even the Pacific Ocean. As previously stated, ${ }^{131} \mathrm{I},{ }^{132} \mathrm{I},{ }^{132} \mathrm{Te},{ }^{134} \mathrm{Cs}$, and ${ }^{137} \mathrm{Cs}$ were the main kinds of radionuclides, and Cs occupied the most adsorption sites $[2,8] .{ }^{134}$ Cs possesses a high chemical activity and relatively short half-life. The Cs ion was the most easily dissolved in the environment and then disappeared among these fission products $[9,10]$.

Aside from the severe environmental issues and the serious impact on humans, there was a significant influence caused on an economic scale. The direct economic losses of this accident reached USD 211 billion, and 656 companies went bankrupt in the Tohoku region $[11,12]$. Subsequently, the recovery expense was a large budget spent on policies concerning the recovery of infrastructure, agriculture, industry and society. However, the most direct impact of this accident was on the electricity system in Japan. It was calculated that $30 \%$ of the electricity supply in Japan depended on nuclear power in 2010 from over 50 nuclear power plants [13,14]. This accident induced the fuel consumption for a brief period for the electricity supply in Japan, before the recovery of the nuclear power plant. However, carbon emissions are rigorously controlled in Japan. Therefore, it conflicts with the economic revival and carbon emission reduction policy were caused and promulgated [15]. At that moment, the most important matter that needed to be was the release of Cs and other radionuclides. Usually, radionuclides can be treated by chemical precipitation, solvent extraction, membrane separation, ion exchange and evaporation. In 2011, Cs adsorption instruments were used in the Fukushima power plant [16]. Some scholars pointed out some other materials, such as a zeolite composite in cesium adsorption. However, the main method is consistent with the fact that ion exchange was most effective and feasible method to be used at that time.

Many scholars studied the adsorption of cesium ion exchange. To date, the main adsorption materials are natural/artificial zeolites, multivalent metal phosphate and composite ion exchange materials, metal ferrocyanide, and titanium silicon compounds. Compared with other materials, zeolite is the most commonly used, classic adsorbent $[17,18]$. Zeolite is a natural mineral with good stability, a high exchange capacity and low material cost, which resulted in it being selected as the best choice for treating low-level radioactive pollutants. Zeolite has a good adsorption performance and is a simple means of forming a stable solidified body with Portland cement. However, due to the small pore size and other reasons, natural zeolite should not be used in its raw state; it is necessary to improve the adsorption performance through appropriate scientific treatment methods by adding it to the experimental comparison of the adsorption treatment for actual radioactive waste liquid $[19,20]$. Theoretically, zeolite is a hydrous aluminosilicate mineral, and possesses a three-dimensional crystal composed of $\mathrm{SiO}_{2}$ and $\mathrm{Al}_{2} \mathrm{O}_{3}$ tetrahedron. In the framework silicate structure of zeolite, $\mathrm{Al}^{3+}$ replaces $\mathrm{Si}^{4+}$ to form a negative charge, so it is attractive to cations, which is also an important power source for zeolite in the adsorption process. According to their different crystal structures, zeolites can be divided into A-type, X-type, Y-type and P-type. According to the different sources of zeolite, it can be divided into natural zeolite and artificial zeolite. In the process of zeolite adsorption, the ratio of silicon to aluminum is the key to affect the adsorption capacity and actual adsorption effect [21-23].

In the present study, natural zeolite and three kinds of modified zeolites are used as adsorbents. The nonradioactive cesium solution is used as a solvent. This paper aims to investigate the adsorption capacity of adsorbents for $\mathrm{Cs}^{+}$, and the effects of solution $\mathrm{pH}$ value, adsorbent dosage, and initial concentration on the adsorption performance of $\mathrm{Cs}^{+}$. The influence of temperature and reaction time on the adsorption performance and removal rate of heavy metal $\mathrm{Cs}^{+}$are also studied. A kinetic and isothermal study are also conducted in this paper in three models, respectively. The characterization and internal 
structure of zeolite are analyzed by SEM and XRD patterns, and the adsorption mechanism of zeolite for heavy metal ions is discussed in the final section.

\section{Materials and Methods}

\subsection{Preparation of Solutions and Sorbents}

The contaminated heavy metal researched in this paper is non-radioactive cesium chloride $(\mathrm{CsCl})$. The selected adsorbent is zeolite, which was purchased in Suzhou, China. In this paper, we used sodium chloride $(\mathrm{NaCl})$, potassium chloride $(\mathrm{KCl})$, and a magnesium chloride $\left(\mathrm{MgCl}_{2}\right)$ solution for zeolite modification, and they were categorized as zeolite, Na-zeolite, K-zeolite and Mg-zeolite. All the reagents or chemicals used in the tests were of an analytical grade. Additionally, a sodium hydroxide $(\mathrm{NaOH})$ and hydrochloric acid $(\mathrm{HCl})$ solution were used to research the effect of $\mathrm{pH}$ and acid-base conditions on the adsorption reaction. All test solutions were prepared with double-distilled water.

\subsection{Experiments}

Five factors were used in this stage, including the initial concentration, adsorbent dosage, solution $\mathrm{pH}$, reaction time, and temperature. The test process was consistent and as follows: $1.0 \mathrm{~g}$ of zeolite was added to $50 \mathrm{~mL}$ of the $\mathrm{Cs}^{+}$solution with different affecting parameters, respectively, and the solid-liquid ratio was 1:50. When the $\mathrm{pH}$ value is 7 , oscillate the solution at the room temperature of $20^{\circ} \mathrm{C}$, at the speed of $150 \mathrm{R} / \mathrm{min}$ for $3 \mathrm{~h}$, equilibrium and static adsorption at $20^{\circ} \mathrm{C}$ for $8 \mathrm{~h}$, and then centrifuge at $4000 \mathrm{R} / \mathrm{min}$ for $10 \mathrm{~min}$. The concentration of each ion in the supernatant was determined by atomic absorption spectrometry, and the adsorption capacity of each ion was calculated by the subtraction method. The factors and parameters are listed in Table 1.

Table 1. Factors and influence parameters in the adsorption tests.

\begin{tabular}{cc}
\hline Factors & Parameters \\
\hline Initial Concentration & $0.3 \mathrm{mmol} / \mathrm{L}, 0.5 \mathrm{mmol} / \mathrm{L}, 0.8 \mathrm{mmol} / \mathrm{L}$, and $1.0 \mathrm{mmol} / \mathrm{L}$ \\
Adsorbent Dosage & $0.1,0.3,0.5,1$, and $1.5 \mathrm{~g}$ \\
Solution $\mathrm{pH}$ & $3,7,11$ \\
Reaction Time & $4,6,10$, and $12 \mathrm{~h}$ \\
Temperature & 40,60, and $80^{\circ} \mathrm{C}$ \\
\hline
\end{tabular}

The Cs ion removal results were calculated based on the equations below $[11,24]$. The equation of the unit adsorption capacity at equilibrium is:

$$
Q_{e}=\frac{\left(C_{0}-C_{e}\right) \times V}{m}
$$

The $Q_{e}$ is the unit adsorption capacity at equilibrium. $V$ represents the volume of the solution, and $\mathrm{m}$ indicates the weight of the zeolite dosage. $C_{0}$ and $C_{e}$ represent the concentration of $\mathrm{Cs}^{+}$before and after adsorption equilibrium (mmol/g), respectively [25]. The removal rate of $\mathrm{Cs}^{+}$is formulated as:

$$
\eta=\frac{C_{0}-C_{t}}{C_{0}} \times 100 \%
$$

In this formula, $C_{0}$ and $C_{t}$ are the concentration before adsorption and the concentration at a different adsorption time.

\subsection{Adsorption Kinetics and Isotherms}

To date, the most widely used adsorption kinetic models include the pseudo-firstorder kinetic model, pseudo-second-order kinetic model, and the intraparticle diffusion kinetic model $[26,27]$. 
The pseudo-first-order kinetic model is:

$$
Q_{t}=Q_{e}\left(1-e^{-k_{1} t}\right)
$$

In this equation, $k_{1}$ is the adsorption rate constant, $t$ represents the reaction time, and $Q_{e}$ and $Q_{t}$ represent the adsorption amount at equilibrium and at a random adsorption time, respectively $[28,29]$.

Then, Equation (4) presented below is the pseudo-second-order kinetic model:

$$
Q_{t}=\frac{k_{2} Q_{e}^{2} t}{1+k_{2} Q_{e} t}
$$

$k_{2}$ is the adsorption rate constant. The third kinetic model used in this paper is the intraparticle diffusion kinetic model, and the equation is written as:

$$
Q_{t}=k_{i n t} t^{1 / 2}+C
$$

In this equation, $k_{\text {int }}$ represents the correlation adsorption rate constants and $C$ is the intercept on the axis. Furthermore, the Langmuir isothermal model, Freundlich isothermal model, and Redlich-Peterson (R-P) isothermal model were conducted for the isotherm studies. The Langmuir isothermal equation is presented below:

$$
Q_{e}=\frac{Q_{m} K_{L} C_{e}}{1+K_{L} C_{e}}
$$

In this formula, $Q_{e}$ depicts the equilibrium unit adsorption capacity, $Q_{m}$ represents the maximum adsorption capacity, and $K_{L}$ is the equilibrium constant. The equation of the Freundlich isothermal model is shown below:

$$
Q_{e}=K_{F} C_{e}^{1 / n}
$$

The $K_{F}$ value is the Freundlich adsorption characteristic constant. Finally, the equation of the Redlich-Peterson ( $\mathrm{R}-\mathrm{P})$ isothermal model is:

$$
Q_{e}=\frac{K_{R P} C_{e}}{1+a_{R P} C_{e}^{\beta}}
$$

$K_{R P}$ and $a_{R P}$ are the characteristic constants of the Redlich-Peterson (R-P) isothermal model. Additionally, $\beta$ is an index between 0 and 1 . It can be simplified as the Langmuir model and Henry model, while $\beta=1$ and $0[30,31]$.

\subsection{Sorbents Characterization}

SEM and XRD tests were also conducted in this paper for an insight into the micromechanism of the cesium adsorption process. Four SEM images and the chemical component's XRD pattern were analyzed.

\section{Results and Discussion}

\subsection{Experiment Results}

The effect of the initial concentration is shown in Figure 1. With the increase in the initial solution concentration, the unit adsorption capacity $Q_{e}$ also increased. It can be seen from the figure that the unit adsorption capacity of K-zeolite is the highest and the growth rate is the largest, with the adsorption amount reaching nearly $0.024 \mathrm{mmol} / \mathrm{g}$. The adsorption effect of Na-zeolite is also better than that of zeolite. However, the adsorption effect of $\mathrm{Mg}$-zeolite is relatively poor, which may be due to the fact that the silicon aluminum ratio of the original zeolite does not improve in the modification process of Mg-zeolite, which 
also results in the weak attraction of the modified zeolite to metal cations, and thus the adsorption effect decreases.

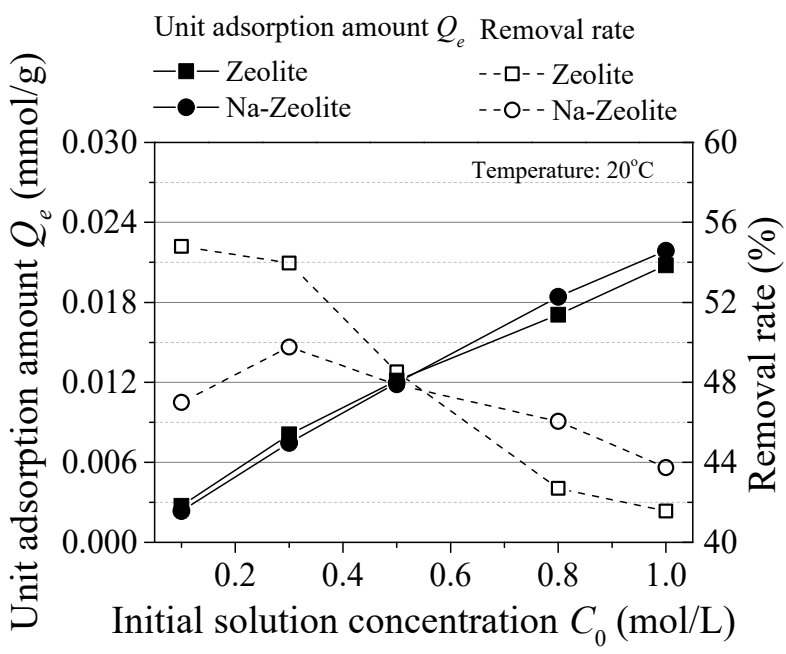

(a)

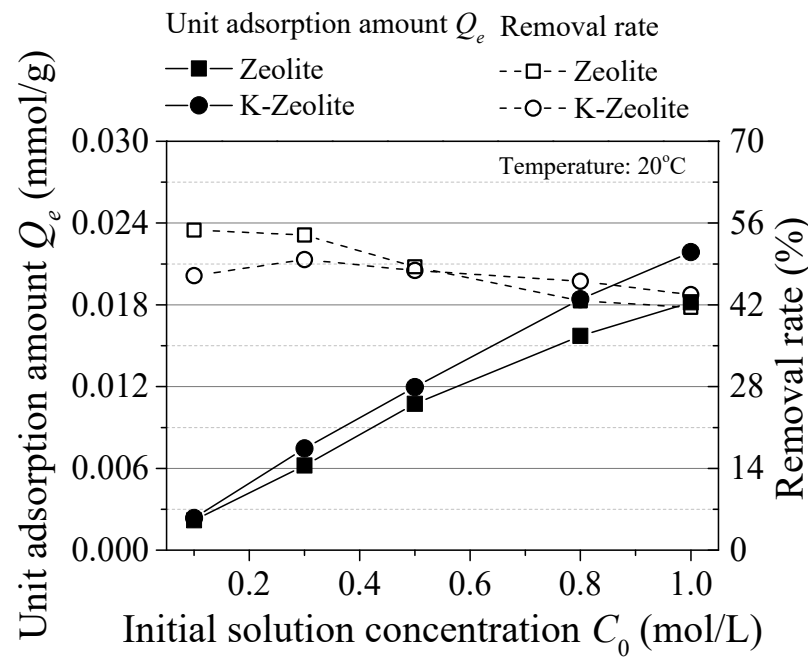

(b)

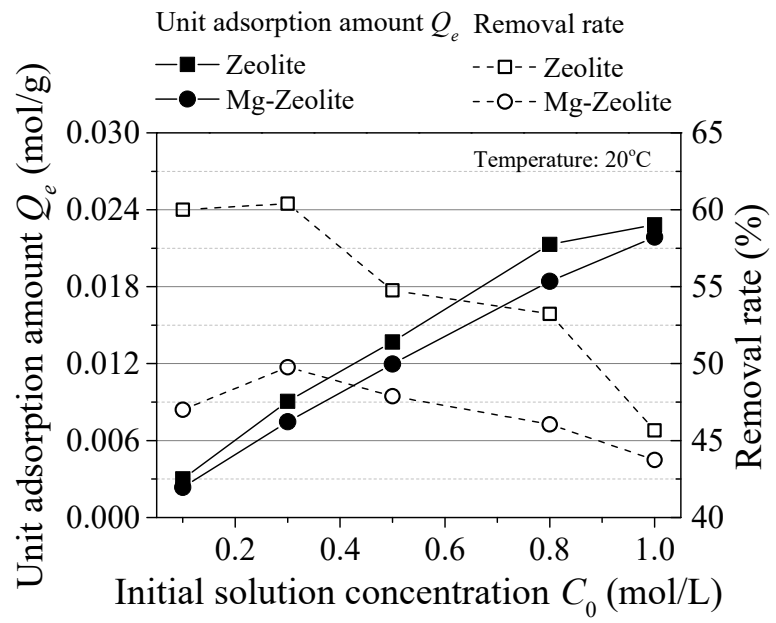

(c)

Figure 1. Effect of initial solution concentration. (a) Na-zeolite, (b) K-zeolite, (c) Mg-zeolite.

When it comes to the adsorption rate, it is below $65 \%$, which suggests that the adsorption process is not satisfactory to some extent. The same trend of these three figures is that the removal rate decreases with the increase in the initial solution concentration. Additionally, $0.1 \mathrm{~mol} / \mathrm{L}$ seems to be the optimal value. The component generated after the reaction may be hindered on the zeolite surface, and thus interrupt the adsorption reaction. This trend is consistent in other studies, but the adsorption rate is relatively low, as shown in Figure 1 [32].

Figure 2 depicts the effect of zeolite dosage during the adsorption reaction. It can be observed from the figure that the optimal dosage of the other zeolites, except Na-zeolite, is $1.1 \mathrm{~g}$. The general trend is that the unit adsorption capacity decreases with the increase in dosage. The adsorption effect of Mg-zeolite is the best, reaching more than $0.0030 \mathrm{mmol} / \mathrm{g}$ at the dose of $1.1 \mathrm{~g}$. The adsorption effect of K-zeolite is not as good as it is before the modification, which may be due to its metal activity leading to the stagnation of the reaction [33]. 


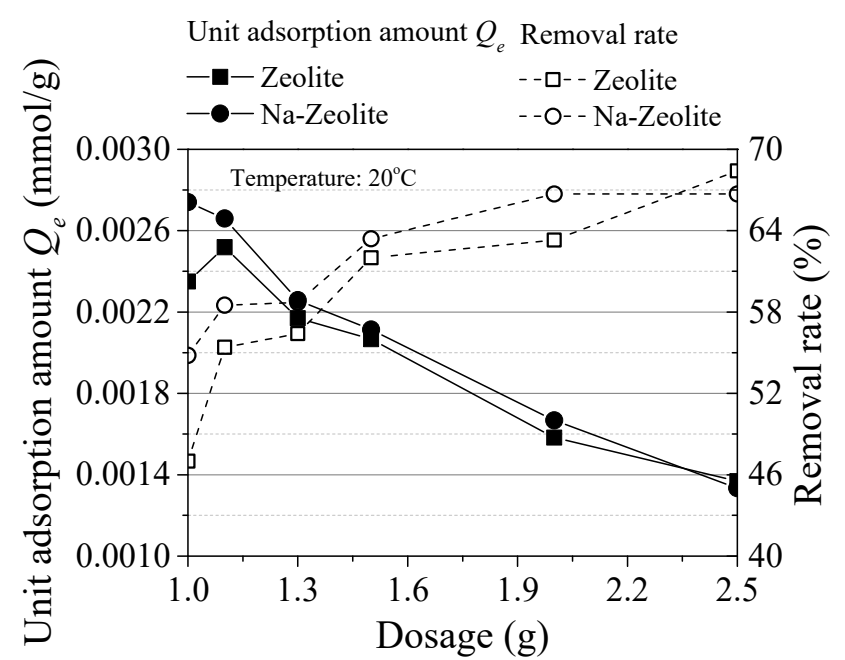

(a)

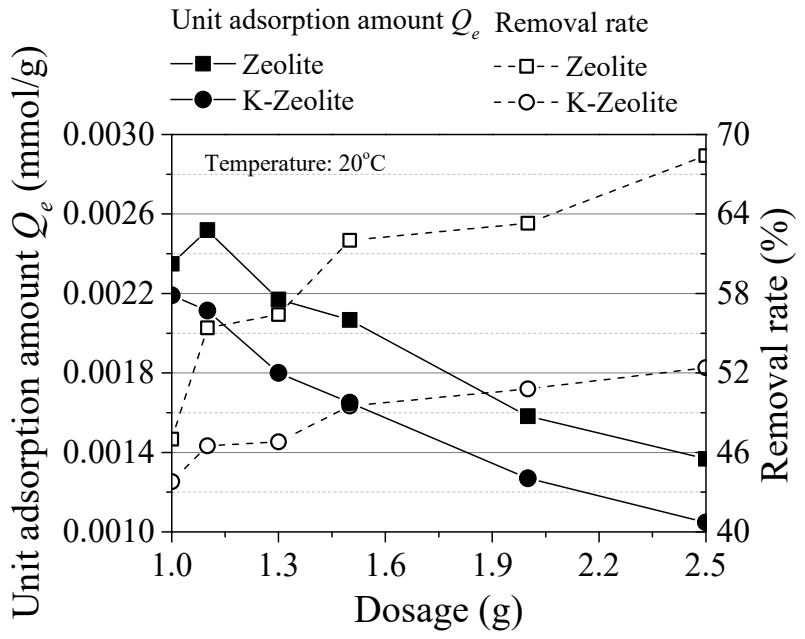

(b)

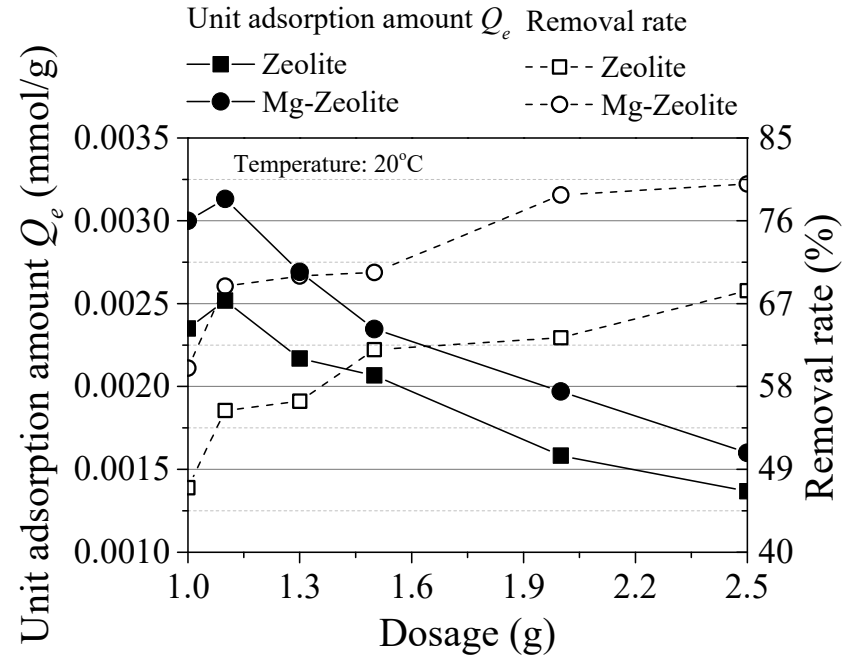

(c)

Figure 2. Effect of zeolite dosage. (a) Na-zeolite, (b) K-zeolite, (c) Mg-zeolite.

The changing trend of the removal rate in Figure 2 is quite different to that presented in Figure 1. Additionally, the adsorption percent is higher in Figure 2, with the maximum in Figure $2 \mathrm{c}$ being close to $85 \%$. The adsorption capacity of Na-zeolite and natural zeolite is close to $70 \%$, while the adsorption rate of K-zeolite is only $52 \%$. This extent of removal rate is comprehensive in the actual application. The removal rate increases with a higher dosage of zeolite, and there is almost no interruption in the curves. It seems that the dosage of $1.1 \mathrm{~g}$ is approaching an optimal amount, because of the high unit adsorption capacity. However, the maximum value of the adsorption rate is observed at $2.5 \mathrm{~g}$, thus the excess dosage provides a greater reaction surface, but reduces the unit adsorption performance [34,35].

The effect of the solution $\mathrm{pH}$ value is shown in Figure 3. Three $\mathrm{pH}$ solutions of $\mathrm{pH}$ 3.0, $\mathrm{pH}$ 7.0, and $\mathrm{pH} 11.0$ were studied. It can be seen that only Mg-zeolite has a better adsorption capacity than natural zeolite in three different acid-base environments, while the adsorption effects of the other two zeolites are not as good as those before modification. Figure 3 depicts that, under the extremely alkaline condition of $\mathrm{pH}$ 11.0, the adsorption effect of zeolite on cesium attains the best results. Under alkaline conditions, more active metal cations are mixed into the solution, which aggravates ion replacement $[36,37]$. 


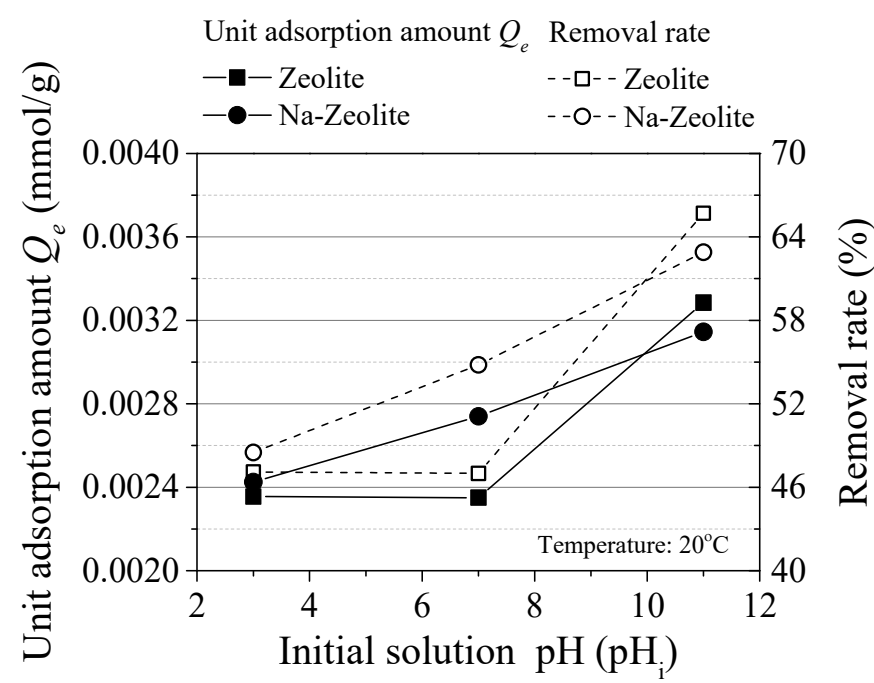

(a)

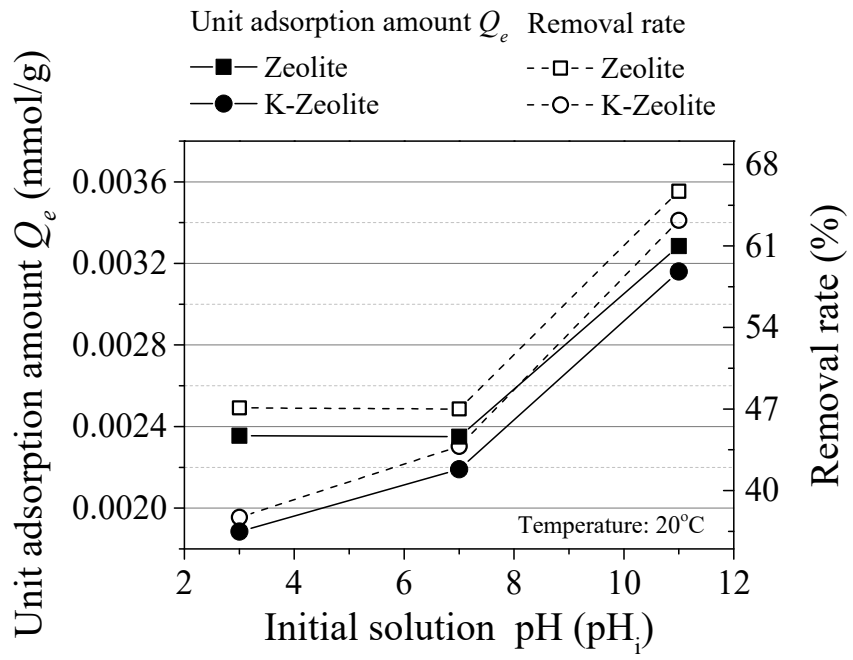

(b)

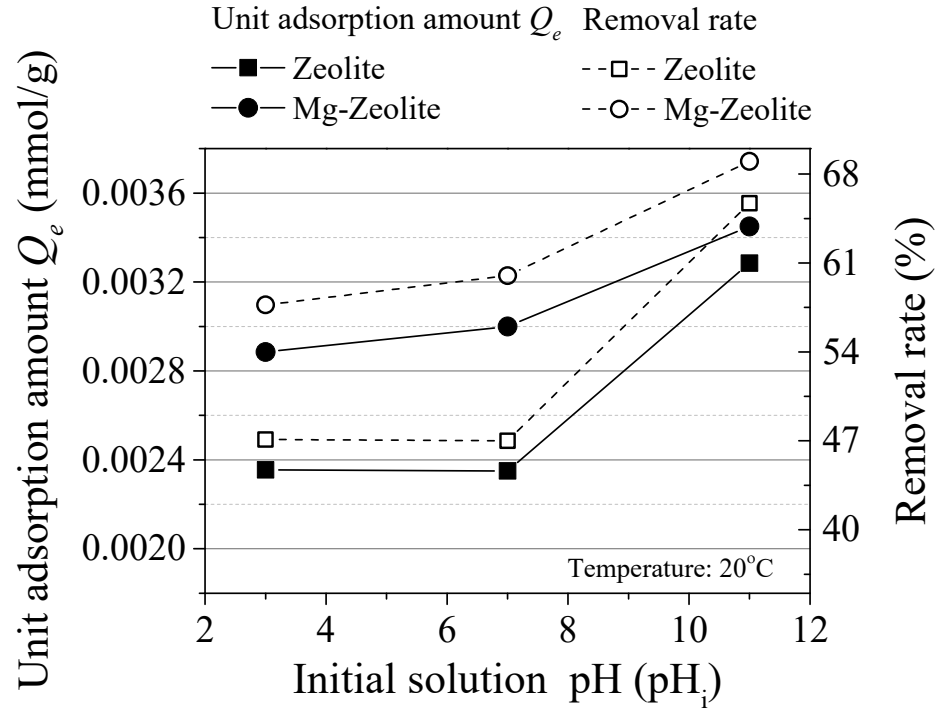

(c)

Figure 3. Effect of solution pH. (a) Na-zeolite, (b) K-zeolite, (c) Mg-zeolite.

The decrease in the adsorption capacity of a sodium molecular sieve may be due to the activity inhibition relationship between the metal ions and $\mathrm{Cs}^{+}$in the solution, which reduces the adsorption activity of the zeolite surface. In terms of the adsorption rate, the maximum adsorption rate of $\mathrm{Mg}$-zeolite is close to $70 \%$, while the adsorption rate of the other two groups of modified zeolites is lower than $60 \%$.

The adsorption capacity during the reaction process is shown in Figure 4 . The starting point is $4 \mathrm{~h}$, and the entire research period is $8 \mathrm{~h}$. Similar to Figure 2, the unit adsorption capacity of Mg-zeolite is much better than Na-zeolite and $\mathrm{K}$-zeolite. The reaction seems to be stable in the $8 \mathrm{~h}$ period presented in Figure $4 \mathrm{a}, \mathrm{b}$, but there is a short increase in in the curve of Mg-zeolite in Figure 4c. The maximum adsorption capacity reaches about $0.0036 \mathrm{mmol} / \mathrm{g}$. The changing trend and mechanism can be summarized as above. The removal rate changes in the opposite trend as a unit adsorption amount. Additionally, a maximum removal rate is also witnessed for Mg-zeolite [38]. 


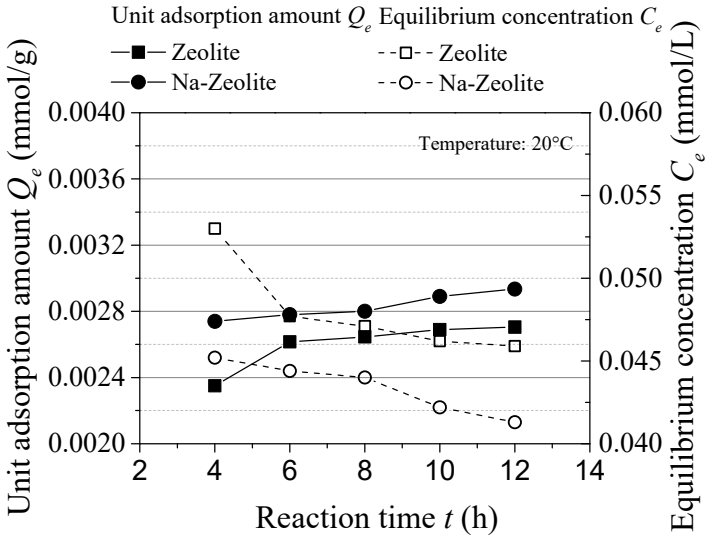

(a)

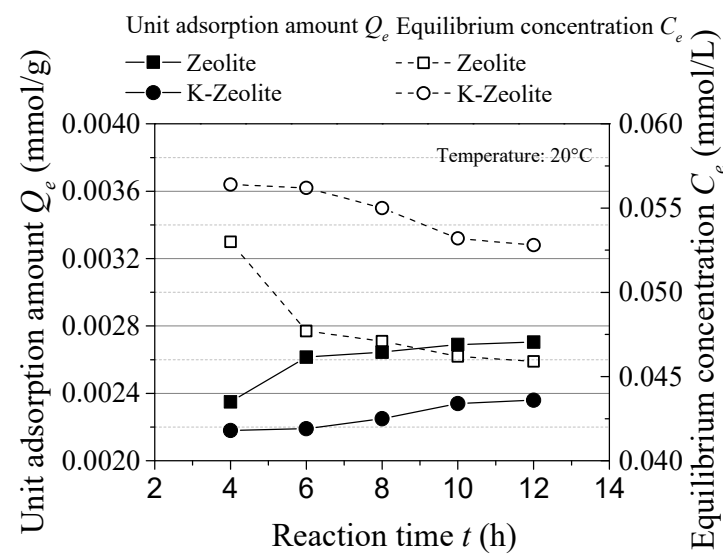

(b)

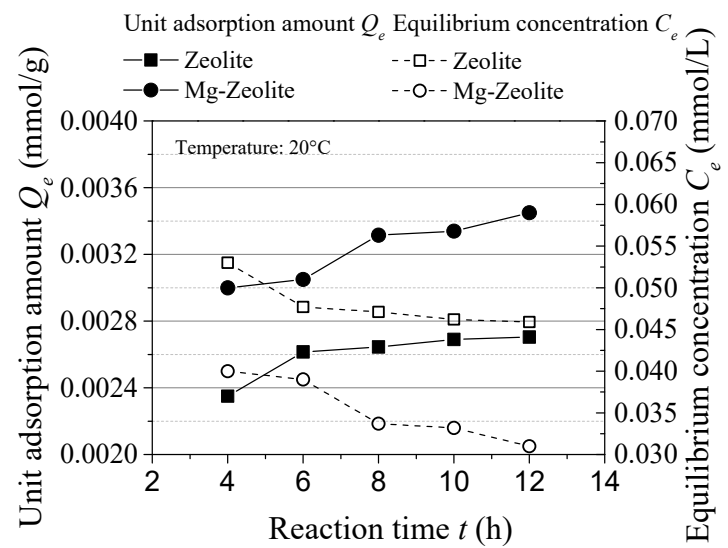

(c)

Figure 4. Effect of reaction time. (a) Na-zeolite, (b) K-zeolite, (c) Mg-zeolite.

The effect of testing the temperature was to investigate the promotion or inhibition of temperature on the adsorption reaction. As shown in Figure 5, the adsorption capacity of Na-zeolite depicts a slight decrease, while that of Mg-zeolite decreases by nearly $10 \%$. Although the maximum unit adsorption capacity of $\mathrm{Mg}$-zeolite reached $0.0034 \mathrm{mmol} / \mathrm{g}$, it continued to decline under the influence of the temperature and was lower than that of Na-zeolite at $80^{\circ} \mathrm{C}$. The trend is similar to Figure 1, in terms of the effect of the initial concentration. The highest removal rate is at the higher temperature of $80^{\circ} \mathrm{C}$. The order of these modified zeolites in the reaction performance is $\mathrm{Mg}$-zeolite $>$ Na-zeolite $>\mathrm{K}$-zeolite [39].

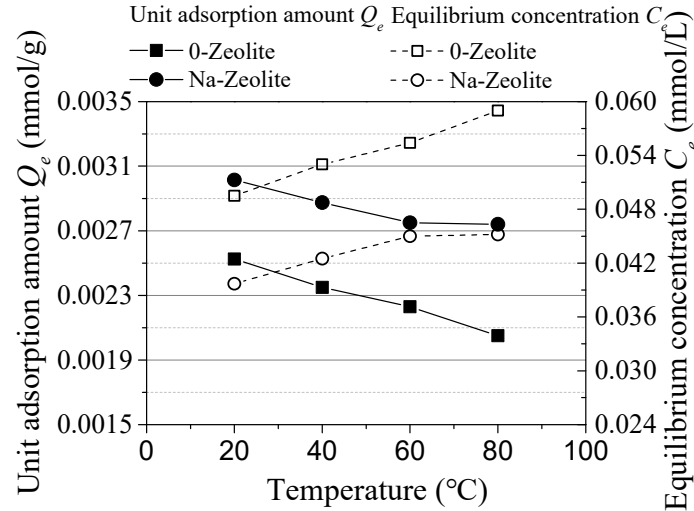

(a)

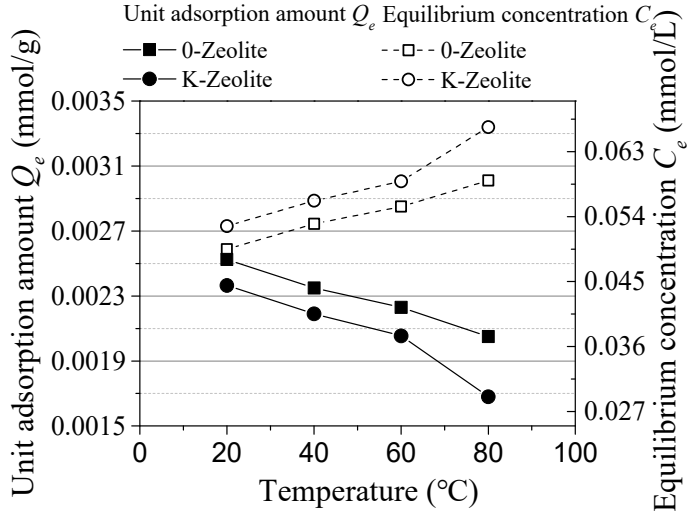

(b)

Figure 5. Cont. 


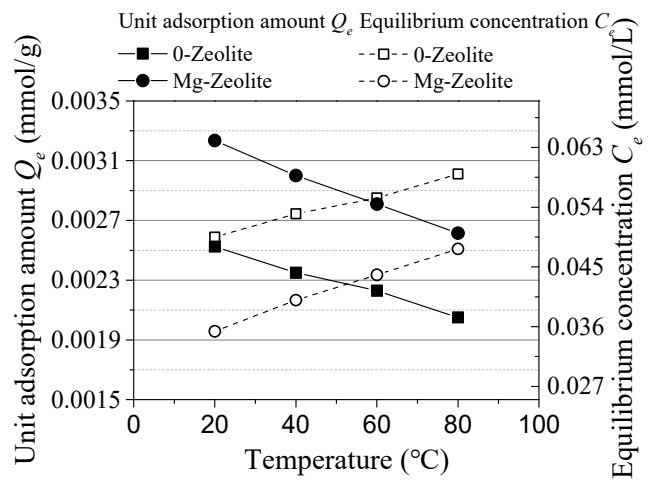

(c)

Figure 5. Effect of temperature. (a) Na-zeolite, (b) K-zeolite, (c) Mg-zeolite.

\subsection{Adsorption Isotherms}

Three different isothermal adsorption models were fitted in this section. The fitting curve is shown in Figure 6. The value of $K^{L}$ is related to the type of adsorbent, and adsorbate and temperature. The greater the $K_{L}$ value, the better of the adsorption capacity [40,41]. From the curves, we can see that the R-P model in Figure $6 \mathrm{c}$ fits better than the other two.

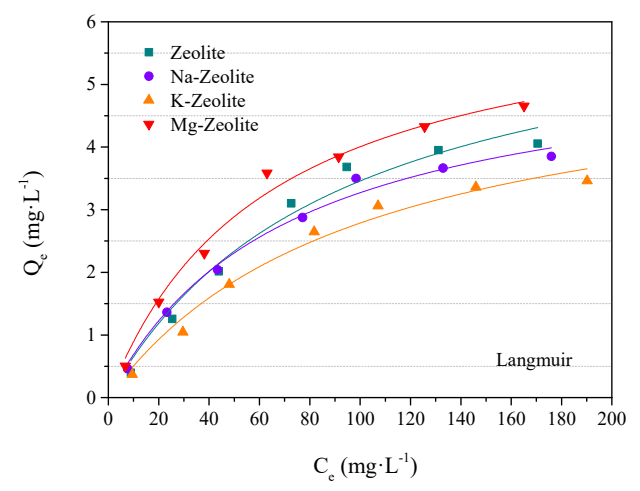

(a)

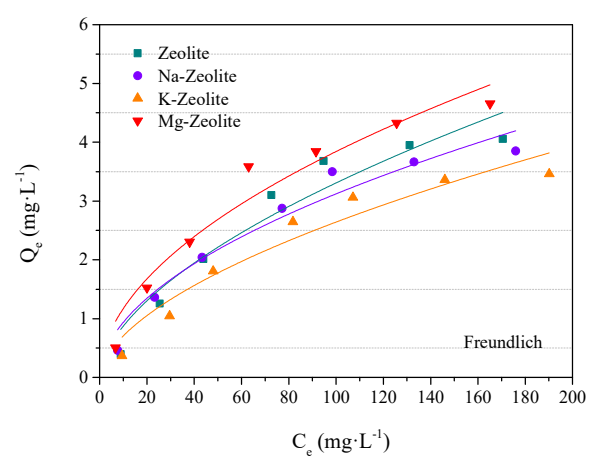

(b)

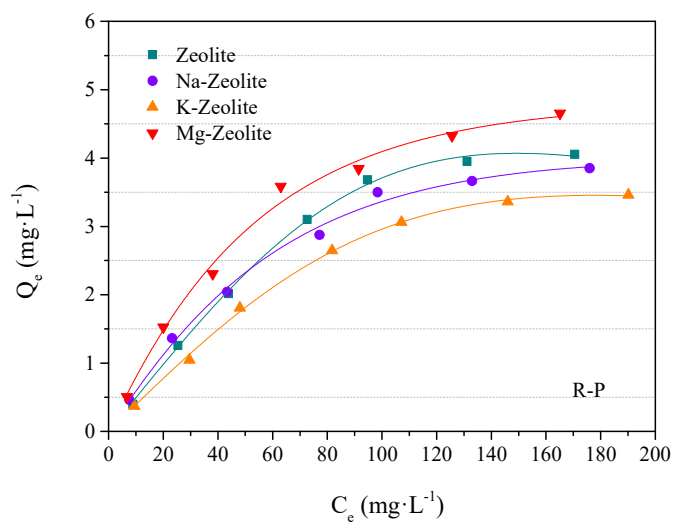

(c)

Figure 6. Isothermal model for cesium adsorption. (a) Langmuir isothermal model, (b) Freundlich isothermal model, (c) Redlich-Peterson isothermal model.

The detailed fitting parameters for cesium adsorption is shown in Table 2. $R^{2}$ reflects the fitting degree of the curve, and the fitting $R^{2}$ of the R-P model is the highest at around 0.990 . The $Q_{m}$ of Mg-zeolite is the highest, and represents a greater reaction area on the surface of zeolite. The ion exchange efficiency is poor in K-zeolite, and similar in zeolite and Na-zeolite. 
Table 2. Isothermal model parameters for cesium adsorption.

\begin{tabular}{ccccccccccc}
\hline Model & \multicolumn{3}{c}{ Langmuir Isothermal Model } & \multicolumn{3}{c}{ Freundlich Isothermal Model } & \multicolumn{4}{c}{ Redlich-Peterson Isothermal Model } \\
\hline Type & $\begin{array}{c}Q_{m} \\
(\mathrm{mg} / \mathrm{g})\end{array}$ & $K_{L}$ & $R^{2}$ & $\begin{array}{c}K \\
(\mathrm{mg} / \mathrm{g})\end{array}$ & $1 / n$ & $R^{2}$ & $\begin{array}{c}K_{R P} \\
(\mathrm{~L} / \mathrm{g})\end{array}$ & $\begin{array}{c}a_{R P} \\
(\mathrm{~L} / \mathrm{mg})\end{array}$ & $\beta$ \\
Zeolite & 5.60 & 0.0140 & 0.989 & 0.230 & 0.579 & 0.923 & 0.049 & $1.16 \times 10^{-5}$ & 2.23 \\
Na-zeolite & 5.69 & 0.0130 & 0.987 & 0.282 & 0.522 & 0.947 & 0.061 & 0.001 & 1.37 \\
K-zeolite & 5.57 & 0.0099 & 0.979 & 0.189 & 0.573 & 0.932 & 0.039 & $3.49 \times 10^{-6}$ & 1.98 & 0.998 \\
Mg-zeolite & 6.53 & 0.0159 & 0.987 & 0.357 & 0.516 & 0.944 & 0.083 & 0.003 & 1.30 \\
\hline
\end{tabular}

According to the three models, the R-P model represents the best fitting. The value of $1 / n$ represents the adsorption efficiency (generally between 0 and 1 ), and the value represents the influence of the mass concentration on the adsorption capacity. The smaller the $1 / n$, the better the adsorption performance [42]. The $1 / n$ of Mg-zeolite is the smallest, which means that the adsorption capacity is the best. This is consistent with the above test results. The Mg-zeolite possesses the best adsorption performance with the $1 / n$ of 0.516 . Furthermore, the fitting of Mg-zeolite presents the lowest $R^{2}$. However, the minimum is also 0.989 , which supports and validates the model fitting [43].

\subsection{Adsorption Kinetics}

The fitting curve of the three kinetic models are shown in Figure 7. The intragranular diffusion model seems to depict a better fitting, compared with the pseudo-first-order kinetic model and pseudo-second-order kinetic model.

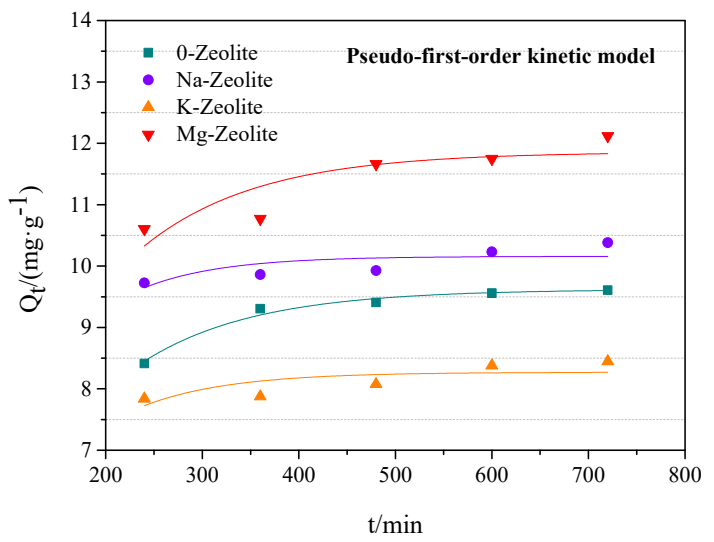

(a) Pseudo-first-order kinetic model

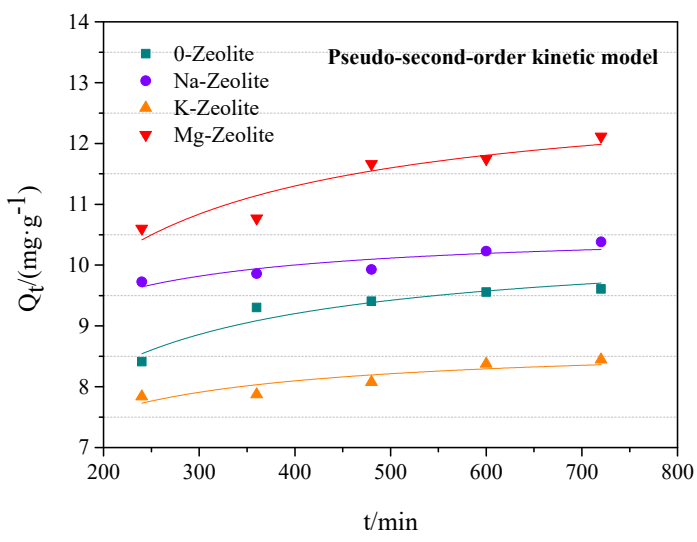

(b)

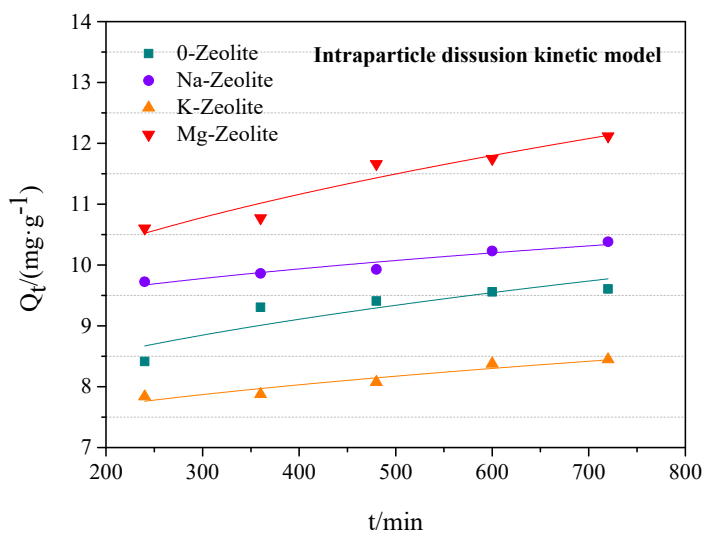

(c)

Figure 7. Kinetic model for cesium adsorption. (a) Pseudo-first-order kinetic model, (b) Pseudosecond-order kinetic model, (c) Intragranular diffusion model. 
The kinetic model parameters for cesium adsorption are shown in Table 3. In this table, the equilibrium adsorption capacity $(9.12,9.66,7.77$, and $11.35 \mathrm{mg} / \mathrm{g})$ and $(9.92,10.10,8.22$, and $12.47 \mathrm{mg} / \mathrm{g}$ ) is presented in these two models, respectively.

Table 3. Kinetic model parameters for cesium adsorption.

\begin{tabular}{cccccccccc}
\hline Model & \multicolumn{2}{c}{ Pseudo-First-Order Kinetic Model } & \multicolumn{2}{c}{ Pseudo-Second-Order Kinetic Model } & \multicolumn{3}{c}{ Intragranular Diffusion Model } \\
\hline Type & $\begin{array}{c}k_{1} \\
(\mathrm{mg} / \mathrm{g})\end{array}$ & $\begin{array}{c}Q_{e} \\
(\mathrm{mg} / \mathrm{g})\end{array}$ & $R^{2}$ & $\begin{array}{c}k_{2} \\
(\mathrm{~g} / \mathrm{mg} \cdot \mathrm{min})\end{array}$ & $\begin{array}{c}Q_{e} \\
(\mathrm{mg} / \mathrm{g})\end{array}$ & $R^{2}$ & $\begin{array}{c}k_{\text {int }} \\
\left(\mathrm{g} / \mathrm{mg} \cdot \mathrm{min}^{1 / 2}\right)\end{array}$ & $\begin{array}{c}C \\
(\mathrm{mg} / \mathrm{g})\end{array}$ & $R^{2}$ \\
Zeolite & 0.0086 & 9.12 & 0.977 & 0.0018 & 9.92 & 0.894 & 0.097 & 6.66 & 0.728 \\
Na-zeolite & 0.0122 & 9.66 & 0.382 & 0.0039 & 10.10 & 0.736 & 0.059 & 8.26 & 0.907 \\
K-zeolite & 0.0111 & 7.77 & 0.376 & 0.0037 & 8.22 & 0.721 & 0.060 & 6.33 & 0.888 \\
Mg-zeolite & 0.0084 & 11.35 & 0.665 & 0.0013 & 12.47 & 0.840 & 0.142 & 7.82 \\
\hline
\end{tabular}

The fitting of the pseudo-first-order seems to be poor, and the pseudo-second-order is comprehensively better. However, the whole adsorption process is well fitted to the intragranular diffusion, which means that the reaction is in the form of a physical and chemical reaction, combined with intragranular diffusion [44].

\subsection{Sorbent's Micro-Scope Characterization}

The difference in the surface of the zeolite before and after adsorption is obvious, as shown in Figure 8. After the reaction, cesium is adsorbed on the surface of the zeolite to form a flocculent component. The newly formed component blocks the zeolite surface and affects the adsorption activity to a certain extent. That is why K-zeolite represents a poor adsorption performance. In contrast, $\mathrm{Mg}$-zeolite possesses larger voids and therefore provides more reaction points. In general, $\mathrm{K}$ ions with a strong activity may possess a poor capacity for cesium adsorption in the solution, where ion competition occurs, while Mg-zeolite has a better adsorption reaction [45].

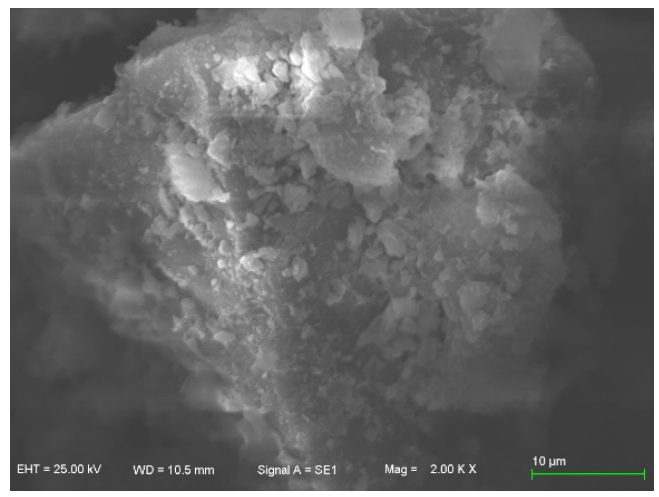

(a)

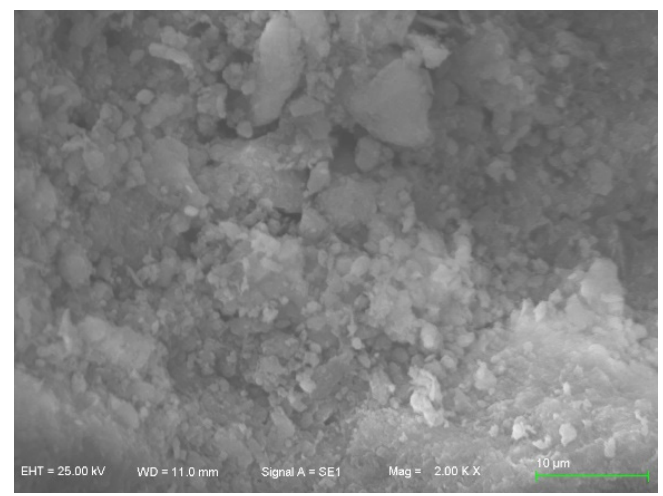

(c)

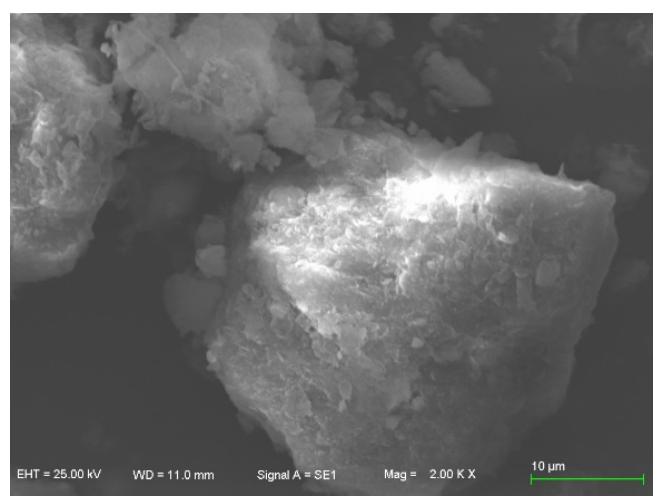

(b)

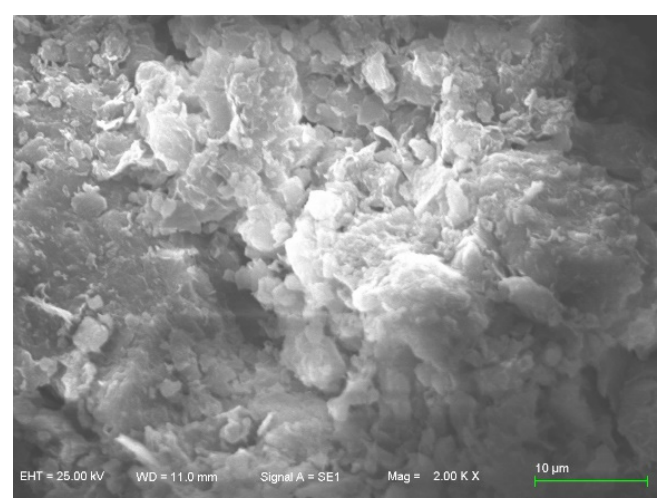

(d)

Figure 8. SEM images on the surface of zeolite. (a) Zeolite, before adsorption, (b) Zeolite, after adsorption, (c) Mg-zeolite, before adsorption, (d) Mg-zeolite, after adsorption. 
Figure 9 depicts the $\mathrm{XRD}$ pattern of zeolite after the adsorption process. The zeolite used in this test is mainly composed of calcium zeolite $\left(\mathrm{Ca}\left[\mathrm{Al}_{2} \mathrm{Si}_{3} \mathrm{O}_{10}\right] \cdot 3 \mathrm{H}_{2} \mathrm{O}\right)$, which is reflected in the figure. The adsorption effect of zeolite mainly depends on two aspects. The first aspect is the internal pore size, which is explained in Figure 8. On the other hand, the most essential factor is that the aluminum in zeolite replaces the amount of silicon in the silica tetrahedron in the zeolite cell. In the zeolite adsorption test, the more $\mathrm{Al}^{3+}$ replaces $\mathrm{Si}^{2+}$, the more cation exchange sites and the greater the exchange capacity. It is obvious that the $\mathrm{Si}^{2+}$ (quartz) content of Mg-zeolite after the reaction is significantly lower than that of the other zeolites [46]. The content of K-zeolite is the highest, which also proves the reason for its poor adsorption effect. Other parts in the figure are relevant reaction products, while the main components of gismondine and quartz mainly appear around $20^{\circ}$ and $40^{\circ}$.

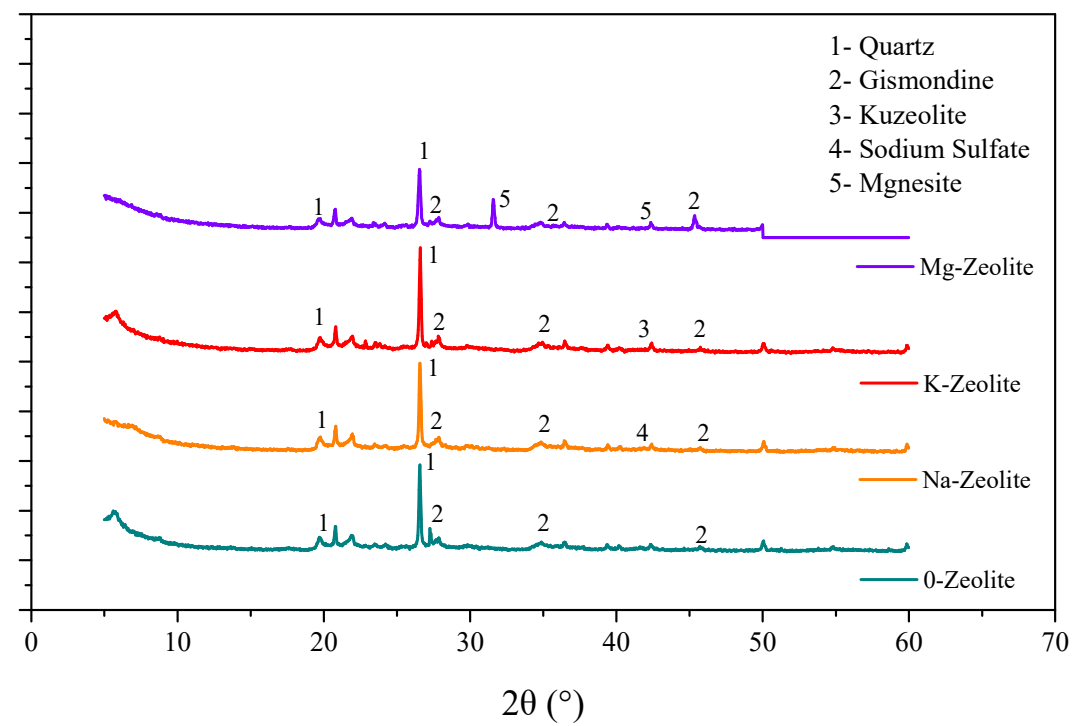

Figure 9. XRD pattern of zeolite.

The adsorption capacity of the cesium ion by different adsorbents is shown in Table 4 . The adsorption capacity of Mg-zeolite is comprehensive in this table. However, compared with nano-sized materials, greater surface contact and full-scale reaction points may lead to better adsorption performances.

Table 4. Adsorption capacity of the cesium ion by different adsorbents.

\begin{tabular}{ccc}
\hline Adsorbents & Capacity $(\mathbf{m g} / \mathbf{g})$ & References \\
\hline Mg-zeolite & 6.53 & This paper \\
Marble & 2.373 & {$[47]$} \\
Nano-Fe/Cu-zeolite & 77.51 & {$[48]$} \\
Prussian blue-modified magnetite & 16.2 & {$[49]$} \\
Magnetic chitosan & 3.86 & {$[50]$} \\
\hline
\end{tabular}

\section{Conclusions}

This paper investigated the adsorption tests via natural zeolite (zeolite) and modified zeolite (Na-zeolite, K-zeolite, and Mg-zeolite). The dosage of zeolite, the initial concentration of the solution, $\mathrm{pH}$ value (acid-base environment), reaction time, and temperature are the five factors observed in this paper. The adsorption isotherm and kinetics were analyzed. The SEM and XRD were also studied for a micro-scope insight into adsorption characterizations. The results are summarized as follows:

(1) The unit adsorption capacity changes in the same trend as an effect of the initial concentration and reaction time. It was also the same on the effect of the sorbent dosage and temperature. In these four groups, the removal rate changes in the reverse 
direction as the unit adsorption amount. Thus, an alkaline solution environment is better for cesium adsorption.

(2) The test data is in better fitting in the Redlich-Peterson isothermal model and intragranular diffusion model. The adsorption reaction is in the form of both physical and chemical adsorption, combined with intragranular diffusion. In this small-scale experiment, the highest adsorption capacity is in Mg-zeolite at $6.53 \mathrm{mg} / \mathrm{g}$.

(3) More reaction points may emerge on the surface of zeolite, and Mg-zeolite presents the best adsorption capacity in this study, where the surface crystal structure of Mg-zeolite is complex and diverse, and the amount of $\mathrm{Al}^{3+}$ that replaces $\mathrm{Si}^{2+}$ is comprehensive compared with other zeolites.

Author Contributions: Conceptualization: J.S.; methodology: J.M.; validation, J.C.; formal analysis: Y.Z. and X.L.; investigation: J.S., J.C. and Y.Z.; resources: J.S.; data curation: J.C. and Y.Z.; writingoriginal draft preparation: J.C. and X.L.; writing—review and editing: X.P. and Q.T.; supervision: X.P. and J.M.; project administration: X.P. All authors have read and agreed to the published version of the manuscript.

Funding: The research presented here is supported by the National Natural Science Foundation of China (52078317), the Natural Science Foundation of Jiangsu Province for Excellent Young Scholars (BK20211597), a project from the Bureau of Housing and Urban-Rural Development of Suzhou (2021-25; 2021ZD02; 2021ZD30), the Bureau of Geology and Mineral Exploration of Jiangsu (2021KY06), China Tiesiju Civil Engineering Group (2021-19), CCCC First Highway Engineering Group Company Limited (KJYF-2021-B-19), and CCCC Tunnel Engineering Company Limited (8gs-2021-04).

Data Availability Statement: I declare that all the data presented in the manuscript were obtained from laboratory tests at Soochow University in Suzhou China. All the laboratory testing data were presented in the figures and tables in the manuscript. We are pleased to share all the raw data. If needed, please contact us via the corresponding author's e-mail.

Conflicts of Interest: The authors declare that they have no conflict of interest.

\section{References}

1. Ishii, K.; Terakawa, A.; Matsuyama, S.; Kikuchi, Y.; Fujishiro, F.; Ishizaki, A.; Osada, N.; Arai, H.; Sugai, H.; Takahashi, H.; et al. Reducing logistical barriers to radioactive soil remediation after the Fukushima No. 1 nuclear power plant accident. Nucl. Instrum. Methods Phys. Res. Sect. B-Beam Interact. Mater. Atoms 2014, 318, 70-75. [CrossRef]

2. Zhao, R.; Wu, D.; Patti, S. A bibliometric analysis of carbon labeling schemes in the Period 2007-2019. Energies 2020, 13, 4233. [CrossRef]

3. Inui, T.; Yasutak, T.; Endo, K.; Katsumi, T. Geo-environmental issues induced by the 2011 off the Pacific Coast of Tohoku Earthquake and tsunami. Soils Found. 2012, 52, 856-871. [CrossRef]

4. Zhao, R.; Wang, X.Q.; Chen, X.L.; Liu, Y.Y. Impacts of different aged landfill leachate on PVC corrosion. Environ. Sci. Pollut. Res. 2019, 26, 18256-18266. [CrossRef] [PubMed]

5. Chino, M.; Nakayama, H.; Nagai, H.; Terada, H.; Katata, G.; Yamazawa, H. Preliminary estimation of release amounts of I-131 and Cs-137 accidentally discharged from the Fukushima Daiichi Nuclear Power Plant into the atmosphere. J. Nucl. Sci. Technol. 2011, 48, 1129-1134. [CrossRef]

6. Song, J.H.; Kim, T.W. Severe accident issues raised by the Fukushima accident and improvement suggested. Nucl. Eng. Technol. 2014, 46, 207-216. [CrossRef]

7. Lingyu, W.; Teng, L.; Xiuting, D.; Maobing, P.; Songtao, X.; Wen, Z. Thiophene-based MOFs for iodine capture: Effect of pore structures and interaction mechanism. Chem. Eng. J. 2021, 425, 130578.

8. Lelieveld, J.; Kunkel, D.; Lawrence, M. Global risk of radioactive fallout after major nuclear reactor accidents. Atmos Chem. Phys. 2012, 12, 4245-4258. [CrossRef]

9. Koo, Y.H.; Yang, Y.S.; Song, K.W. Radioactivity release from the Fukushima accident and its consequences: A review. Prog. Nucl. Energy 2014, 74, 61-70. [CrossRef]

10. Sasaki, T.; Tanaka, S. Magnetic separation of cesium ion using Prussian blue modified magnetite. Chem. Lett. 2012, 41, 32-34. [CrossRef]

11. Zhao, R.; Li, M.; Ma, S.D.; Yang, T.X.; Jing, L.Y. Material selection for landfill leachate piping by using a grey target decision-making approach. Environ. Sci. Pollut. Res. 2021, 28, 494-502. [CrossRef]

12. Kajitani, Y.; Chang, S.E.; Tatano, H. Economic impacts of the 2011 Tohoku-Oki earthquake and tsunami. Earthq. Spectra 2013, 29, S457-S478. [CrossRef] 
13. Zhang, Q.; Mclellan Benjamin, C. Review of Japan's power generation scenarios in light of the Fukushima nuclear accident. Int. J. Energy Res. 2014, 38, 539-550. [CrossRef]

14. Vivoda, V. Japan's energy security predicament post-Fukushima, energy policy. Energy Policy 2012, 46, 135-143. [CrossRef]

15. Wen, Z.; Yingxin, M.; Xihong, H.; Peng, C.; Song, Z.; Chengde, H.; Yuxin, W.; Jing, C. Robust porous polymers bearing phosphine oxide/chalcogenide ligands for volatile iodine capture. Chem. Eng. J. 2020, 379, 122365.

16. Tsukada, T.; Uozumi, K.; Hijikata, T.; Koyama, T.; Ishikawa, K.; Ono, S.; Suzuki, S.; Denton, M.S.; Keenan, R.; Bonhomme, G. Early construction and operation of highly contaminated water treatment system in Fukushima Daiichi Nuclear Power Station (I)-Ion exchange properties of KURION herschelite in simulating contaminated water. J. Nucl. Sci. Technol. 2014, 51, 886-893. [CrossRef]

17. Saber-Samandari, S.; Saber-Samandari, S.; Nezafati, N.; Yahya, K. Efficient removal of lead (II) ions and methylene blue from aqueous solution using chitosan/Fe-hydroxyapatite nanocomposite beads. J. Environ. Manag. 2014, 146, 481-490. [CrossRef]

18. Zhao, R.; Wu, D.; Zhang, J. Policy Implications on Carbon Labeling Scheme Toward Carbon Neutrality in China. Front. Environment. Sci. 2021, 482. [CrossRef]

19. Wen, Z.; Xiuting, D.; Yingxin, M.; Yuxin, W.; Jing, C. Constructing adjacent phosphine oxide ligands confined in mesoporous $\mathrm{Zr}-\mathrm{MOF}$ for uranium capture from acidic medium. J. Mater. Chem. A 2021, 9, 16685-16691.

20. Lasheen, M.R.; Ammar, N.S. Speciation and stabilization of some heavy metals in the sediments from drains, Egypt. Desalination Water Treat. 2014, 52, 3271-3279. [CrossRef]

21. Wen, Z.; An, B.; Qingyuan, J.; Luofu, M.; Song, Z.; Yuxin, W.; Jing, C. pK(a)-Directed Incorporation of Phosphonates into MOF-808 via Ligand Exchange: Stability and Adsorption Properties for Uranium. ACS Appl. Mater. Interfaces 2019, 11, 33931-33940.

22. Tang, Q.; Tang, X.W.; Li, Z.Z.; Chen, Y.M.; Kou, N.Y.; Sun, Z.F. Adsorption and desorption behaviour of Pb(II) on a natural kaolin: Equilibrium, kinetic and thermodynamic studies. J. Chem. Technol. Biotechnol. 2009, 84, 1371-1380. [CrossRef]

23. Peng, C.; Xihong, H.; Maobin, P.; Xiuting, D.; Song, Z.; Wen, Z. Iodine Capture Using Zr-Based Metal-Organic Frameworks (Zr-MOFs): Adsorption Performance and Mechanism. ACS Appl. Mater. Interfaces 2020, 12, 20429-20439.

24. Tang, Q.; Tang, X.W.; Li, Z.Z.; Wang, Y.; Hu, M.M.; Zhang, X.J.; Chen, Y.M. Zn(II) Removal with Activated Firmiana Simplex Leaf: Kinetics and Equilibrium Studies. J. Environ. Eng. (ASCE) 2012, 138, 19199. [CrossRef]

25. Tang, Q.; Liu, W.; Li, Z.Z.; Wang, Y.; Tang, X.W. Removal of Aqueous Cu(II) with Natural Kaolin: Kinetics and Equilibrium Studies. Environ. Eng. Manag. J. 2018, 17, 467-476. [CrossRef]

26. Tang, Q.; Katsumi, T.; Inui, T.; Li, Z.Z. Membrane behavior of bentonite-amended compacted clay towards Zn(II) and Pb(II). Membr. Water Treat. 2015, 6, 393-409. [CrossRef]

27. Tang, Q.; Chu, J.M.; Wang, Y.; Zhou, T.; Liu, Y. Characteristics and factors influencing Pb(II) desorption from a Chinese clay by citric acid. Sep. Sci. Technol. 2016, 51, 2734-2743. [CrossRef]

28. Tang, Q.; Zhou, T.; Gu, F.; Wang, Y.; Chu, J.M. Removal of Cd(II) and Pb(II) from soil through desorption using citric acid: Kinetic and equilibrium studies. J. Cent. South Univ. 2017, 24, 1941-1952. [CrossRef]

29. Tang, Q.; Liu, W.; Wang, H.Y.; Cheng, R.; Qian, Y.F. Membrane behavior of bentonite-amended Fukakusa clay in K, Na and Ca solutions. J. Cent. South Univ. 2016, 23, 3122-3131. [CrossRef]

30. Tang, Q.; Wang, H.Y.; Tang, X.W.; Wang, Y. Removal of aqueous Ni(II) with carbonized leaf powder: Kinetic and equilibrium studies. J. Cent. South Univ. 2016, 27, 778-786. [CrossRef]

31. Tang, Q.; Shi, P.X.; Yuan, Z.; Shi, S.J.; Xu, X.J.; Katsumi, T. Potential of zero-valent iron in remediation of Cd(II) contaminated soil: From laboratory experiment, mechanism study to field application. Soils Found. (JGS) 2019, 59, 2099-2109. [CrossRef]

32. Huang, Y.L.; Ning, Y.; Zhang, T.; Wu, J.J. Measuring Carbon Emissions of Pavement Construction in China. Sustainability 2016, 8, 723. [CrossRef]

33. Zhao, R.; Zhou, X.; Han, J.J.; Liu, C.L. For the sustainable performance of the carbon reduction labeling policies under an evolutionary game simulation. Technol. Forecast. Soc. Chang. 2016, 112, 262-274. [CrossRef]

34. Ofomaja, A.E.; Pholosi, A.; Naidoo, E.B. Kinetics and competitive modeling of cesium biosortion onto chemically modified pine cone powder. J. Taiwan Inst. Chem. Eng. 2013, 44, 943-951. [CrossRef]

35. Ozeroglu, C.; Dogan, E.; Keçeli, G. Investigation of Cs(I) adsorption on densely crosslinked poly(sodium methacrylate) from aqueous solutions. J. Radioanal. Nucl. Chem. 2011, 289, 577-586. [CrossRef]

36. Lingyu, W.; Peng, C.; Xiuting, D.; Wen, Z.; Song, Z.; Songtao, X.; Yinggen, O. Porous MOF-808@PVDF beads for removal of iodine from gas streams. RSC Adv. 2020, 10, 44679-44687.

37. Kumagai, S.; Hayashi, K.; Kameda, T.; Yoshioka, T. Removal and condensation of cesium ion from water phase into ionic associate phase using tetraphenylborate. J. Soc. Remediat. Radioact. Contam. Environ. 2016, 4, 239-245.

38. Thilagavathy, P.; Santhi, T. Kinetics, isotherms and equilibrium study of $\mathrm{Co}(\mathrm{II})$ adsorption from single and binary qqueous solutions by Acacia nilotica leaf carbon. Chin. J. Chem. Eng. 2014, 22, 1193-1198. [CrossRef]

39. Liu, Z.; Ciais, P.; Deng, Z.; Davis, S.J.; Zheng, B.; Wang, Y.; Cui, D.; Zhu, B.; Dou, X.; Ke, P.; et al. Carbon Monitor, a near-real-time daily dataset of global CO emission from fossil fuel and cement production. Sci. Data 2020, 7, 392. [CrossRef]

40. Zhang, Z.; Li, M.; Chen, W.; Zhu, S.; Liu, N.; Zhu, L. Immobilization of lead and cadmium from aqueous solution and contaminated sediment using nano-hydroxyapatite. Environ. Pollut. 2010, 158, 514-519. [CrossRef]

41. Mohammad, A.M.; Eldin, T.A.S.; Hassan, M.A.; El-Anadouli, B.E. Efficient treatment of lead-containing wastewater by hydroxyapatite/chitosan nanostructures. Arab. J. Chem. 2017, 10, 683-690. [CrossRef] 
42. Rahman, M.M.; Sheikh, T.A.; Asiri, A.M.; Awual, M.R. Development of 3-methoxyaniline sensor probe based on thin Ag2O@La2O3nanosheets for environmental safety. N. J. Chem. 2019, 43, 4624632. [CrossRef]

43. Erzsébet, S.B.; Melinda, C.; Réka, B.; Csavdari, A.A. Influence of synthesis method of nanohydroxyapatite-based materials on cadmium sorption processes. J. Iran. Chem. Soc. 2014, 11, 53-68.

44. Hokkanen, S.; Bhatnagar, A.; Repo, E.; Lou, S.; Sillanpää, M. Calcium hydroxyapatite micro-fibrillated cellulose composite as a potential adsorbent for the removal of $\mathrm{Cr}(\mathrm{VI})$ from aqueous solution. Chem. Eng. J. 2016, 283, 445-452. [CrossRef]

45. Long, Y.; Jiang, J.; Hu, J.; Hu, X.; Yang, Q.; Zhou, S. Removal of Pb (II) from aqueous solution by hydroxyapatite/carbon composite: Preparation and adsorption behavior. Colloids Surf. A Physicochem. Eng. Asp. 2019, 577, 471-479. [CrossRef]

46. Yang, Z.; Liang, L.; Yang, W.; Shi, W.; Tong, Y.; Chai, L.; Gao, S.; Liao, Q. Simultaneous immobilization of cadmium and lead in contaminated soils by hybrid bio-nanocomposites of fungal hyphae and nano-hydroxyapatites. Environ. Sci. Pollut. Res. 2018, 25, 119711980. [CrossRef]

47. Eljamal, O.; Shubair, T.; Tahara, A.; Sugihara, Y.; Matsunaga, N. Iron based nanoparticles-zeolite composites for the removal of cesium from aqueous solutions. J. Mol. Liq. 2019, 277, 613-623. [CrossRef]

48. El-Khaiary, M.I.; Malash, G.F. Common data analysis errors in batch adsorption studies. Hydrometallurgy 2011, 105, 314. [CrossRef]

49. Scheckel, K.G.; Sparks, D.L. Temperature Effects on Nickel Sorption Kinetics at the Mineral-Water Interface. Soil Sci. Soc. Am. J. 2011, 65, 719. [CrossRef]

50. Zhang, X.; Lin, S.; Chen, Z.; Megharaj, M.; Naidu, R. Kaolinite-supported nanoscale zero-valent iron for removal of Pb ${ }^{2+}$ from aqueous solution: Reactivity, characterization and mechanism. Water Res. 2011, 25, 3481. [CrossRef] 